\title{
TRATAMENTO DE ÁGUA RESIDUÁRIA À BASE DE BIOCARVÃO DO BAGAÇO DE LARANJA PARA A IRRIGAÇÃO DA CULTURA DO RABANETE ${ }^{1}$
}

\author{
Roseanne Santos de Carvalho ${ }^{2}$ \\ Gregorio Guirado Faccioli \\ Maria de Lara Palmeira de Macedo Arguelho \\ Erik Santos Passos \\ Beatriz Feitosa Sandes dos Santos \\ Rômulo Alves de Oliveira
}

\begin{abstract}
RESUMO
Diversos estudos apontam a escassez da água como um problema mundial. A utilização de águas residuárias torna-se um componente necessário para a gestão dos recursos hídricos, por dar suporte ao abastecimento de água bem como ser responsável por proporcionar uma destinação apropriada aos efluentes, no qual pode ser destacado o reuso na agricultura. A metodologia consistiu em montar dois sistemas filtrantes em escala de bancada (biocarvão do bagaço da laranja e carvão comercial) para promover um tratamento complementar das águas residuárias oriundas da ETE Rosa Elze e irrigar a cultura do rabanete. Foram realizadas as análises agronômicas da cultura, bem como análises químicas da água da concessionária local, do efluente e do solo. A irrigação com efluente tratado após filtragens não influenciou nas variáveis agronômicas da planta. Os resultados com o efluente filtrado com o biocarvão, apesar de não ter atendido às normas da OMS, apresentou os melhores valores entre os tratamentos. Nas análises físico-químicas, pode-se observar que todos os parâmetros foram atendidos. Já os valores da condutividade elétrica das águas alertam ao risco de salinização do solo. O biocarvão à base do bagaço de laranja apresentou resultados promissores no que diz respeito a ser um tratamento terciário em efluente doméstico pós-tratamento secundário para irrigação na agricultura.
\end{abstract}

Palavras-chave: Efluentes. Agricultura. Adsorção.

\section{WASTE WATER TREATMENT BASED ON ORANGE BAGOUS BIOCARBON FOR THE IRRIGATION OF RABANET CROP}

\begin{abstract}
Several studies point to water scarcity as a global problem. The use of wastewater becomes a necessary component for the management of water resources, as it supports water supply as

\footnotetext{
${ }^{1}$ Como citar este artigo: CARVALHO, R. S. et al. Tratamento de água residuária à base de biocarvão do bagaço de laranja para a irrigação da cultura do rabanete. ForScience, Formiga, v. 9, n. 2, e01067, jul./dez. 2021. DOI: $10.29069 /$ forscience.2021v9n2.e1067.
}

${ }^{2}$ Autor para correspondência: Roseanne Santos de Carvalho, e-mail: roseanne.carvalho@ifs.edu.br.
\end{abstract}


well as being responsible for providing an appropriate destination for effluents, in which reuse in agriculture can be highlighted. The methodology consisted of setting up two filtering systems on a bench scale (orange bagasse biochar and commercial charcoal) to promote a complementary treatment of wastewater from the Rosa Elze ETE and to irrigate the radish crop. Agronomic analyzes of the crop were carried out, as well as chemical analyzes of water from the local concessionaire, effluent and soil. Irrigation with treated effluent after filtering did not influence the agronomic variables of the plant. The results with the effluent filtered with biochar, despite not having met the WHO norms, showed the best values among the treatments. In the physicochemical analyses, it can be observed that all parameters were met. The values of electrical conductivity of water, on the other hand, warn of the risk of soil salinization. Biochar based on orange bagasse showed promising results in terms of being a tertiary treatment in domestic effluent after secondary treatment for irrigation in agriculture.

Keywords: Effluents. Agriculture. Adsorption.

\section{INTRODUÇÃO}

Desde a revolução industrial, o desenvolvimento de atividades agrícolas e industriais aumentou consideravelmente, sendo a água utilizada em diversas etapas de processos produtivos. Apesar dos benefícios que a revolução industrial proporcionou na qualidade de vida dos cidadãos, ocasionou um acréscimo na degradação ambiental. Segundo Cahill (2003), o impacto ambiental do consumismo do "homem moderno" tornou-se evidente a partir dos últimos 30 anos do século XX. Abreu (2007) incrementa que o crescimento do consumo de energia, de água e de alimentos não permite que a taxa de renovação destes recursos seja superior ao seu consumo, podendo tornar-se recursos não renováveis.

Diversos estudos apontam a escassez da água como um problema mundial. Pode-se destacar a má distribuição hídrica, no qual algumas regiões são privilegiadas com o elevado quantitativo de volume de água, como no caso do Brasil, a região do Amazonas. Já outras localidades, como alguns países da África, apresentam graves problemas decorrentes da falta de água. Contudo vale ressaltar o levantamento realizado pela Agência Nacional de Águas (ANA, 2011), no qual as regiões Norte e Nordeste do Brasil são as que têm, relativamente, os maiores problemas nos sistemas produtores de água. No Nordeste, inclusive o percentual do potencial hídrico do país é de $18 \%$ e a região também concentra os maiores problemas com disponibilidade de mananciais, por conta da escassez de chuvas. Segundo Rebouças, Braga e Tundisi (2006), a escassez da água acarretará em problemas nas esferas política, econômica, sanitária, podendo até originar conflitos análogos aos causados pelo domínio do petróleo.

Cunha (2008) cita que a disponibilidade de água decresce cada vez mais elevando a necessidade de se rever o sistema de consumo bem como o estabelecimento de políticas que 
alavanquem o uso sustentável. Contudo, as fontes alternativas de abastecimento de água devem contemplar a necessidade de garantia da água em quantidade e qualidade necessárias a cada fim, garantindo inclusive a saúde pública dos usuários. A autora sinaliza a importância da conservação e do reuso de água para a promoção da sustentabilidade dos recursos hídricos.

Por citar a sustentabilidade, dados atuais do Ministério da Agricultura (BRASIL, 2020) indicam que anualmente o Brasil é o responsável por 18 milhões de toneladas ou cerca de $30 \%$ da safra mundial da laranja. Conforme Fiorentin et al. (2010), o resíduo da laranja pode causar muitos problemas econômicos e ambientais devido principalmente à sua elevada fermentação. Usualmente, parte do bagaço tem sido empregado como aditivo na alimentação de ruminantes na forma de silagem. Contudo, a indústria tem grande interesse em desenvolver novas aplicações para o bagaço da laranja, destacando-se a utilização deste material como adsorvente no tratamento de efluentes.

Diante de todo o contexto, a utilização de águas residuárias torna-se um componente necessário para a gestão dos recursos hídricos, por dar suporte ao abastecimento de água bem como responsável por proporcionar uma destinação apropriada aos efluentes, no qual pode ser destacado o reuso na agricultura, aliando ao fato de que utilizar o bagaço da laranja para a produção de biocarvão irá proporcionar uma destinação apropriada ao referido resíduo agrícola.

Diante disso, o objetivo desta pesquisa consiste no estudo da utilização de um tratamento de água residuária composto por filtros de biocarvão de bagaço da laranja para a promoção da irrigação da cultura do rabanete.

\section{MATERIAL E MÉTODOS}

A matéria prima utilizada para carbonização (via mufla) foi o bagaço da laranja, proveniente das lanchonetes e restaurantes do Campus São Cristóvão da Universidade Federal de Sergipe. Para otimização da etapa de carbonização em mufla, foram realizados quatro ensaios com o bagaço de laranja moído a diferentes temperaturas. Nos pré-testes para a produção do biocarvão, foram utilizadas as temperaturas de $350,450,550$ e $650{ }^{\circ} \mathrm{C}$, cujo critério de seleção da temperatura de produção do biocarvão foi baseado no acompanhamento das variáveis condutividade elétrica e $\mathrm{pH}$ em conjunto com a análise da coloração, visando a observação do teor de sais em ambiente ácido e básico, já que é possível gerar biocarvões a estas temperaturas. 


\subsection{Ensaios}

Foi necessária a montagem de dois filtros adsorventes (biocarvão do bagaço da laranja e carvão comercial ativado) para promover o pós-tratamento das águas residuárias oriundas da ETE Rosa Elze e irrigar a cultura do rabanete. Foram realizadas as análises agronômicas da cultura (massa do bulbo, diâmetro longitudinal e diâmetro transversal), bem como análises químicas da água, do efluente ( $\mathrm{pH}$, condutividade elétrica, fósforo total, magnésio, manganês, cobre total, ferro total e zinco total) e do solo (matéria orgânica, sódio, porcentagem de sódio trocável, $\mathrm{pH}$, potássio e fósforo), estas últimas análises realizadas em duplicata.

Todas as colunas de filtragem foram constituídas por garrafas plásticas acopladas de diâmetro aproximado de $5 \mathrm{~cm}$ e comprimento de $22 \mathrm{~cm}$ apoiadas em bancada de madeira (Figura 1); o biocarvão e o carvão comercial ativado foram dispostos no interior de sua respectiva coluna com altura de $5 \mathrm{~cm}$ e entre camadas de dolomita com altura na parte superior de $1 \mathrm{~cm}$ e na parte inferior de $2 \mathrm{~cm}$. A função da dolomita consistiu em promover o confinamento dos materiais adsorventes, já as propriedades de adsorção e remoção de substâncias químicas e orgânicas cabem aos carvões ativados (TEIXEIRA; SANTOS; SANTANA, 2015). Os tubos foram dispostos verticalmente e em suas extremidades inferiores foram colocadas telas presas a elásticos para a contensão de todo o sistema. Foram colocados recipientes plásticos abaixo dos filtros para as devidas coletas do efluente filtrado e medidos os volumes em beckers.

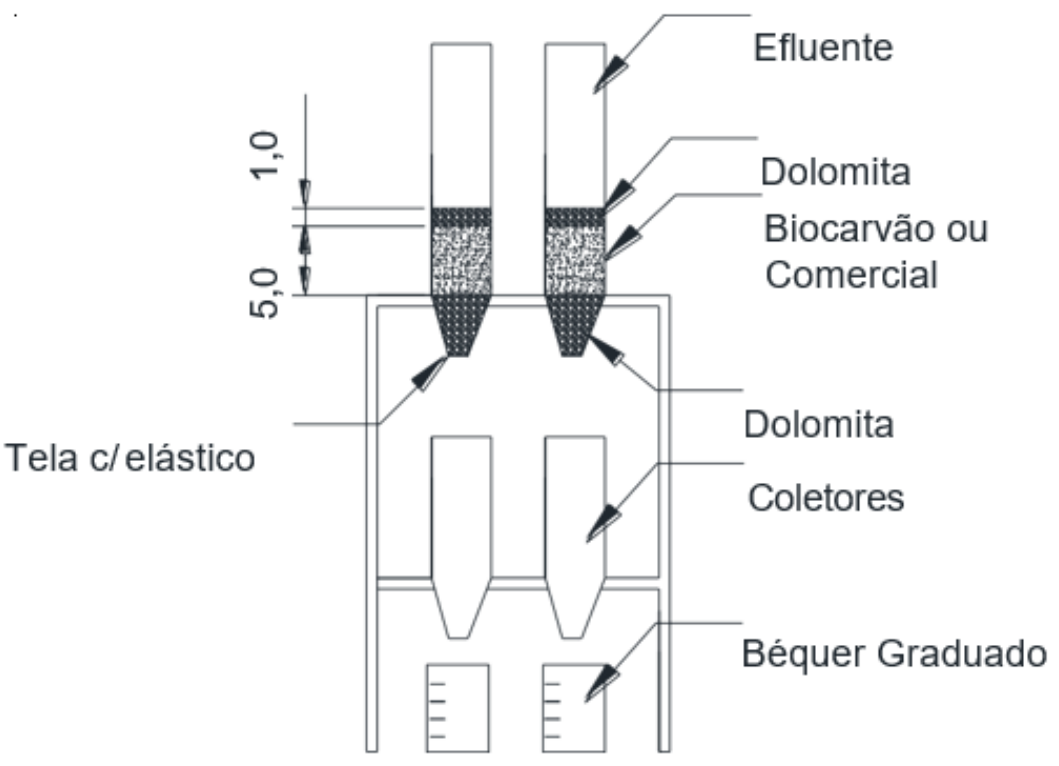

Figura 1 - Esquema da estrutura para a execução da filtragem da água residuária doméstica e respectiva coleta dos efluentes* 
**unidades em centímetros

Fonte: Autores (2020).

Para promover a alimentação dos filtros, foram adaptadas mangueiras em seringas plásticas para que não houvesse impacto da altura de queda do efluente no sistema. Diariamente foi requerida uma coluna de efluente de $14 \mathrm{~cm}$ em cada filtro e, após a filtragem, foram medidos os volumes filtrados e medidos $\mathrm{pH}$ e condutividade elétrica de todos os quatros tratamentos: com água da companhia de abastecimento local (AP), água residuária tratada (EFL), água residuária tratada após filtragens com o biocarvão (BIO) e água residuária tratada após filtragens com o carvão comercial (COM) para irrigação da cultura.

O efluente utilizado na pesquisa foi proveniente da Estação de Tratamento de Esgoto (ETE) do bairro Rosa Elze. A ETE trata as águas residuárias geradas pelos bairros do Rosa Elze e do Eduardo Gomes, atuando com vazão aproximada de $7,6 \mathrm{~L} \mathrm{~s}^{-1}$, composta por cinco lagoas de estabilização disposta em série, sendo duas facultativas e três de maturação perfazendo uma área total de $29.650 \mathrm{~m}^{2}$ (CARVALHO et al., 2013).

Para a análise da resposta biológica dos carvões estudados, a cultura irrigada escolhida foi o rabanete devido ao fato de possuir um ciclo curto bem como a possibilidade do cultivo em vasos em casa de vegetação.

\subsection{Análise agronômica e química da água, do efluente e do solo (resposta biológica)}

Para análise da resposta biológica do biocarvão ativado, os experimentos foram conduzidos em uma casa de vegetação em condições controladas, onde a cultura do rabanete foi irrigada. Foram utilizados 12 vasos para a irrigação com volume aproximado de 1,5 litros, tendo os quatro tratamentos com três repetições cada (Figura 2).

O solo utilizado para o cultivo do rabanete foi coletado no Campus Rural da UFS, sendo devidamente peneirado e homogeneizado. A composição do solo foi realizada a partir de um ensaio feito no Instituto Tecnológico e de Pesquisas do Estado de Sergipe (ITPS) com uma amostra de 500 gramas. Tendo o perfil da composição do solo, foram realizados os cálculos para a calagem por ter sido identificado um baixo $\mathrm{pH}$ do solo, bem como o índice de saturação de bases. Dessa forma, foram introduzidas 2,4 gramas de calcário magnesiano em cada vaso contendo o solo e foi promovida a umidificação de todos os vasos por 30 dias como forma de melhorar a incorporação do material. Nos vasos testemunhos, irrigados com água da companhia de abastecimento local (AP), foram homogeneizados 55,40 gramas de terra vegetal. 


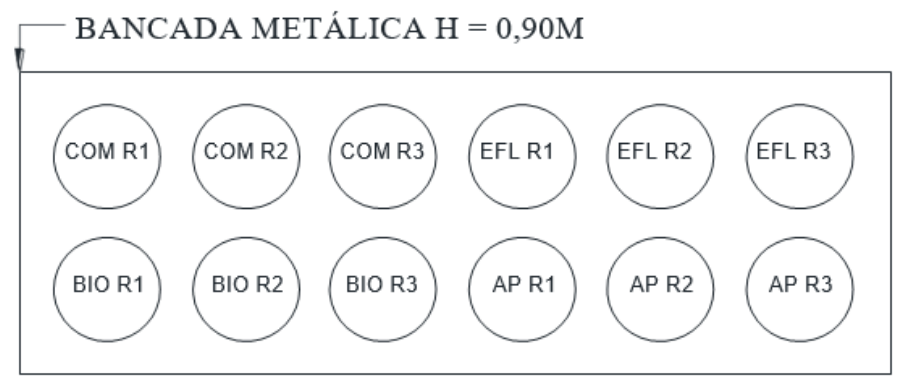

Figura 2 - Vista superior dos vasos da cultura do rabanete*

**Três repetições: R1, R2 e R3

Fonte: Próprios autores (2020).

Após o término da calagem, foi realizada a adubação de $0,4 \mathrm{~g}$ de superfosfato triplo nos vasos testemunhos AP de acordo com a indicação para a cultura (FILGUEIRA, 2012) e a semeadura, no qual foram utilizadas as sementes adquiridas da empresa ISLA Sementes, Rabanete Saxa - Raphanus sativus. A semeadura foi feita em fileira única no centro do vaso conforme Figura 3 e então realizada a irrigação de saturação até a germinação, composta por $400 \mathrm{~mL}$ de água da companhia de abastecimento local uma vez por dia, objetivando a possibilidade de germinações uniformes e um adequado desenvolvimento radicular das plântulas. Após 20 dias da semeadura, quando a germinação em todos os vasos ocorreu de forma satisfatória, foi feito o desbaste para que cada vaso ficasse com uma planta e foi dado início a irrigação diferenciada por tratamentos, com água da companhia de abastecimento local (AP), água residuária tratada (EFL) e água residuária tratada após filtragens (BIO e COM).

O experimento contou com quatro fontes distintas de água: água coletada diariamente em uma torneira, situada no laboratório de química ambiental (LQA/UFS), água residuária tratada, proveniente da ETE Rosa Elze, localizada no município de São Cristóvão/SE, água residuária tratada proveniente da filtragem diária com carvão comercial ativado e água residuária tratada proveniente da filtragem diária com biocarvão.

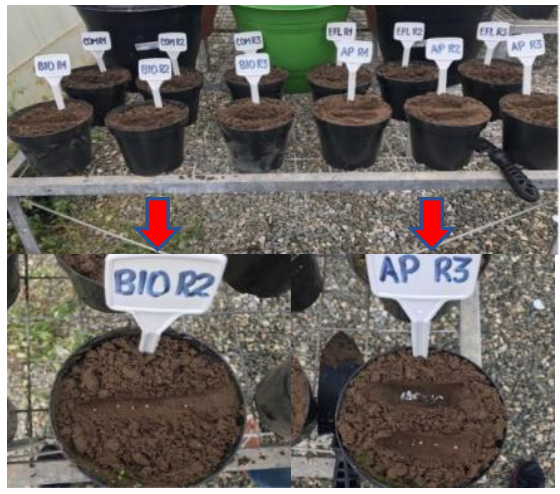

Figura 3 - Vasos semeados. Detalhes: sem e com adubação Fonte: Autores (2020). 
A água residuária foi coletada e transportada semanalmente até o laboratório em reservatório plástico de 10 litros com tampa e acondicionada em reservatórios plásticos de 5 litros com tampa em refrigerador. Cabe salientar que a UFS possui duas fontes distintas de abastecimento de água, uma diretamente fornecida pela companhia de abastecimento de água local (DESO) e a segunda fonte por meio de poços distribuídos ao longo do Campus.

A irrigação diferenciada foi feita diariamente com provetas de $50 \mathrm{~mL}$ e $15 \mathrm{~mL}$ diretamente no solo do vaso, semelhante a uma irrigação por superfície. A quantidade a ser irrigada foi calculada de acordo com o método padrão FAO 56 utilizando a equação de Penman- Monteith, para obtenção da $\mathrm{ET}_{0}$, a evapotranspiração de referência, sendo multiplicada pelo coeficiente de cultivo da cultura $(\mathrm{kc})$ obtendo a evapotranspiração potencial da cultura em mm dia ${ }^{-1}$.

As variáveis meteorológicas utilizadas na equação de Penman-Monteith (temperatura, umidade relativa do ar, radiação solar e velocidade do vento) foram obtidas diariamente por meio da estação meteorológica automática instalada dentro da casa de vegetação e o coeficiente de cultivo do rabanete foi definido pelo documento FAO 56 (ALLEN et al., 2005).

O desenvolvimento da cultura (Figura 4) apresentou-se dentro da normalidade, não houve presença de pragas e doenças típicas da cultura, porém um vaso não apresentou germinação das sementes, contudo encontra-se dentro do percentual de sementes que não germinam conforme orientação do fabricante ISLA sementes.

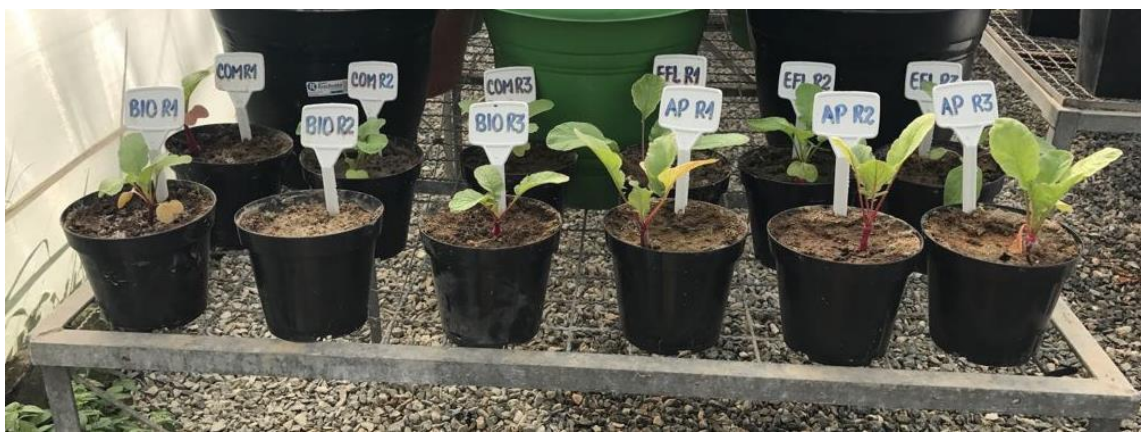

Figura 4 - Desenvolvimento da cultura

Fonte: Autores (2020).

A colheita foi realizada 43 dias após semeadura, portanto as plantas foram retiradas dos vasos de forma a manter a integridade das mesmas, no qual os solos foram colocados em sacos plásticos para a homogeneização dos mesmos com seus tratamentos para posteriores análises da composição de solo no ITPS obedecendo a quantidade mínima para análise de 500 gramas para cada amostra de solo. 
As plantas foram devidamente identificadas, colocadas em sacos plásticos e levadas ao laboratório de química ambiental para obtenção dos parâmetros de massa do bulbo em balança digital, bem como medidas dos diâmetros longitudinais (DL) e diâmetros transversais (DT) com régua graduada. Os dados foram submetidos à análise de variância e as médias dos tratamentos foram comparadas pelo teste de Tukey ao nível de 0,05 de probabilidade no programa estatístico SISVAR.

Quanto às análises físico-químicas das fontes hídricas utilizadas para irrigação, ao longo do experimento foram coletadas duas amostras de cada filtro, de água da companhia de abastecimento local e de efluente coletado direto das lagoas de estabilização, as quais foram imediatamente acondicionadas em recipientes plásticos e levadas ao Instituto Tecnológico de Pesquisas do Estado de Sergipe (ITPS). As análises constituíram na determinação de fósforo total, magnésio, manganês total, cobre, ferro e zinco com o objetivo de observar se o elemento filtrante permitiria a passagem dos nutrientes necessários à irrigação de culturas. As análises de $\mathrm{pH}$ e condutividade elétrica foram realizadas diariamente no próprio LQA com aparelho de pH modelo Ion pHB 500 e condutivímetro modelo Lutren CD- 4301 em beckers de vidro.

Quanto às análises microbiológicas (coliformes termotolerantes), foram coletadas duas amostras de água/efluente de cada um dos quatro tratamentos, as quais foram imediatamente acondicionadas em recipientes de vidro fornecidos pelo ITPS e levadas juntamente com as análises físico-químicas ao ITPS em isopor com gelo no intervalo máximo de uma hora.

Quanto às análises de solo, após a colheita dos rabanetes, os solos de cada tratamento foram homogeneizados e coletados em sacos plásticos devidamente identificados contendo 500 gramas cada e levados ao ITPS para as análises de solos finais. Para mensurar a eficiência dos adsorventes, o procedimento de filtragem foi realizado por duas vezes em ambos os tipos de filtros até a observância de mudança de coloração do efluente.

\section{RESULTADOS E DISCUSSÃO}

Para a produção do biocarvão à base do bagaço da laranja, a seleção da temperatura do biocarvão a ser produzido foi baseada no acompanhamento das variáveis condutividade elétrica e pH em conjunto com a análise da coloração, no qual a análise da coloração permitiu identificar de maneira primária que a partir da temperatura de $550{ }^{\circ} \mathrm{C}$ o biocarvão deixou de transferir para a água filtrada os subprodutos da queima do carvão, ou seja, não apresentando indícios visuais dessa transferência citada. Cabe ressaltar que a condutividade elétrica está 
relacionada ao potencial osmótico do solo que, para que não haja modificação, se utiliza o menor valor e quanto ao $\mathrm{pH}$, é necessário o valor estar mais próximo da zona de neutralidade, portanto, entre o biocarvão produzido a $550{ }^{\circ} \mathrm{C}$ e a $650{ }^{\circ} \mathrm{C}$, o biocarvão a $550{ }^{\circ} \mathrm{C}$ foi o que melhor atendeu aos critérios citados.

\subsection{Análises agronômicas}

De acordo com as análises de variância para as variáveis agronômicas: massa do bulbo, diâmetro transversal e diâmetro longitudinal das plantas não ocorreram diferença estatística significativa de $5 \%$ de probabilidade, portanto a utilização do efluente bem como dos efluentes após filtragens com carvão comercial ativado e o biocarvão não provocaram alterações nas variáveis.

Os resultados obtidos no presente estudo (Tabela 1) apresentaram-se de acordo com os encontrados por Cuba et al. (2015) no cultivo de alface hidropônico com água residuária tratada. Já Costa Júnior et al. (2014) no estudo de irrigação de milho e Oliveira et al. (2013) no estudo de irrigação de moranga, ambas as irrigações com águas residuárias, chegaram a obter valores agronômicos e nutricionais mais elevados comparado com água da concessionária local. É importante salientar que em experimentos com duas variedades de feijão, irrigados com águas residuárias provenientes da mesma estação de tratamento, não foram observadas influências nas características agronômicas avaliadas com nível de significância de $5 \%$, destacando a viabilidade da utilização da água residuária para irrigação de culturas (FACCIOLI et al., 2017).

Tabela 1 - Análise d avariância para massa do bulbo e diâmetros longitudinal e transversal do rabanete

\begin{tabular}{cccc}
\hline Tratamentos* $^{*}$ & Massa bulbo & $\begin{array}{c}\text { Diâmetro } \\
\text { longitudinal }\end{array}$ & $\begin{array}{c}\text { Diâmetro } \\
\text { transversal }\end{array}$ \\
\hline BIO & $2.632500 \mathrm{a} 1 * *$ & $2.700000 \mathrm{a} 1$ & $1.500000 \mathrm{a} 1$ \\
AP & $3.334000 \mathrm{a} 1$ & $3.066667 \mathrm{a} 1$ & $1.600000 \mathrm{a} 1$ \\
$\mathrm{COM}$ & $4.614333 \mathrm{a} 1$ & $3.600000 \mathrm{a} 1$ & $1.766667 \mathrm{a} 1$ \\
$\mathrm{EFL}$ & $6.444333 \mathrm{a} 1$ & $4.200000 \mathrm{a} 1$ & $1.833333 \mathrm{a} 1$ \\
\hline
\end{tabular}

*BIO: filtragem com biocarvão; AP: água da companhia de abastecimento local; COM: filtragem com carvão comercial ativado; EFL: efluente tratado

**a1=notação do programa SISVAR. Significa que não houve diferenciação significativa na variância dos tratamentos

\subsection{Análises da água e de efluentes}


Os resultados referentes à caracterização química da água da torneira do LQA na UFS, do efluente tratado coletado direto da ETE e efluentes após filtragem com carvão comercial ativado e biocarvão em termos de $\mathrm{pH}$ e condutividade elétrica (CE) foram obtidos diariamente no LQA por todo o período da irrigação da cultura do rabanete e podem ser observadas as médias aritméticas na Tabela 2, os parâmetros: fósforo total, magnésio, manganês total, cobre total, ferro total, zinco total e coliformes termotolerantes foram obtidos em dois momentos junto ao ITPS e podem ser observadas na Tabela 2 conjuntamente com os parâmetros da Resolução CONAMA Nº. 357/2005 (BRASIL, 2005).

Ao realizar uma análise das características físico-químicas das quatro fontes de irrigação (Tabela 2) com os determinados pela Resolução CONAMA Nº. 357/2005 (BRASIL, 2005), no tocante a águas de classe 1, destinadas “à irrigação de hortaliças que são consumidas cruas e de frutas que se desenvolvam rentes ao solo e que sejam ingeridas cruas sem remoção de película", pode-se observar que o $\mathrm{pH}$, manganês, ferro total e zinco total se enquadram no estipulado pela citada resolução, viabilizando então todos os tratamentos utilizados quanto aos parâmetros citados.

Sobre o parâmetro da condutividade elétrica, os valores obtidos são inferiores ao que determina a CETESB (2006), no qual cita que a CE das águas residuárias tratadas deverá estar abaixo de $2,9 \mathrm{dS} \cdot \mathrm{m}^{-1}$ (a $25{ }^{\circ} \mathrm{C}$ ) para limitar o risco de salinização do solo, contudo ressalta que as águas residuárias que apresentem condutividade elétrica entre 0,75 e 2,9 dS. $\mathrm{m}^{-1}$ somente podem ser utilizadas para a aplicação em solos bem drenados, sendo que as espécies cultivadas deverão apresentar alta tolerância salina, a CETESB também informa que, para o cobre total, a concentração máxima deve ser de $0,2 \mathrm{mg} \mathrm{L}^{-1}$, portanto tornando aceitáveis os valores obtidos na Tabela 2 .

Segundo Rolim et al. (2016), a presença de macro nutriente (P) nas águas residuárias favorece a fertilização do solo, chegando a eliminar a utilização de fertilizante comercial, trazendo benefícios econômicos além de um possível aumento de produtividade. $\mathrm{O}$ acréscimo desse composto pode-se observar entre AP e EFL no qual após filtragem dos carvões, comportou-se de forma a conservar o teor do macro nutriente no efluente. Conforme a Resolução CONAMA n ${ }^{0} 357 / 2005$, o limite máximo de fósforo total para ambientes lênticos deve ser no máximo de $0,020 \mathrm{mg} \mathrm{L}^{-1}$, portanto nenhum tratamento apresentou-se dentro do parâmetro.

Porém, em estudos realizados por Carvalho et al. (2013), ao utilizarem águas residuárias tratadas por um conjunto em série de lagoas de estabilização, facultativas e de 
maturação para a irrigação de girassol, quantificaram um valor médio de fósforo total correspondente a $2,54 \mathrm{mg} \mathrm{L}^{-1}$, valor abaixo do encontrado por Koraa et al. (2002) no cultivo de batatinha e alface, $2,77 \mathrm{mg} \mathrm{L}^{-1}$ no qual não houve diferença significativa nos parâmetros físico-químicos do solo após as irrigações. Duarte et al. (2008) citaram valores médios entre 2,81 a $1,78 \mathrm{mg} \mathrm{L}^{-1}$ do efluente bem como os diversos tratamentos estudados, portanto, conforme Tabela 2, os valores de fósforo para efluente e após filtragens se aproximaram dos citados acima, podendo-se considerar que o parâmetro não exerceu influência no solo após filtragens.

Tabela 2 - Caracterização físico-química das amostras de água da companhia de abastecimento local, efluente e efluente após filtragens com carvões

\begin{tabular}{|c|c|c|c|c|c|c|}
\hline Parâmetro* & Unidade & $\mathbf{A P} * *$ & EFL*** & BIO*** & $\mathrm{COM}^{* *}$ & $\begin{array}{c}\text { CONAMA } \\
357 / 2005\end{array}$ \\
\hline $\mathrm{pH}$ & - & 6,71 & 6,99 & 7,68 & 7,48 & $6,0-9,0$ \\
\hline $\mathrm{CE}$ & $\mathrm{dS} . \mathrm{m}^{-1}$ & 0,397 & 0,802 & 1,285 & 1,107 & - \\
\hline P total & mgP.L $\mathrm{L}^{-1}$ & 0,286 & 1,420 & 1,443 & 1,516 & 0,020 \\
\hline $\mathrm{Mg}$ & $\mathrm{mgMg} \mathrm{L}^{-1}$ & 4,45 & 4,27 & 5,67 & 3,19 & - \\
\hline $\mathrm{Mn}$ & $m g M n L^{-1}$ & $<0,019$ & $<0,019$ & $<0,019$ & $<0,019$ & 0,1 \\
\hline $\mathrm{Cu}$ total & $\mathrm{mgCu} \mathrm{L}^{-1}$ & $<0,002$ & $<0,002$ & $<0,002$ & $<0,002$ & - \\
\hline Fe total & $\mathrm{mgFe} \mathrm{L}^{-1}$ & 0,178 & 0,090 & 0,023 & 0,045 & 0,3 \\
\hline $\mathrm{Zn}$ total & $\mathrm{mgZn} \mathrm{L}^{-1}$ & 0,075 & 0,045 & 0,045 & 0,035 & 0,18 \\
\hline
\end{tabular}

* CE: condutividade elétrica; P total: fósforo total; Mg: magnésio; Mn: manganês; $\mathrm{Cu}$ total: cobre total; Fe total: Ferro total; Zn total: zinco total

**BIO: filtragem com biocarvão; AP: água da companhia de abastecimento local; COM: filtragem com carvão comercial ativado; EFL: efluente tratado

Conforme as diretrizes da Organização Mundial de Saúde (WHO, 1989), a contagem de coliformes termotolerantes não deverá exceder um limite de 1000 coliformes termotolerantes (NMP) por 100 mililitros; portanto, nenhum dos tratamentos realizados atende ao parâmetro, no entanto vale destacar, conforme Tabela 3, que a filtragem com o biocarvão além de promover a remoção mais eficaz, resultou em valores inclusive aproximados aos da água da companhia de abastecimento local coletada diretamente da torneira do LQA/UFS.

Cabe ressaltar estudos tais como de Carvalho et al. (2013) que reutilizam efluentes domésticos na irrigação de girassóis, Dantas et al. (2014) referência na irrigação de rabanete e Faccioli et al. (2017) na irrigação de duas variedades de feijão-caupi, todos apresentaram resultados para coliformes termotolerantes e Salmonella dentro dos parâmetros da Resolução 
RDC $\mathrm{n}^{\mathrm{o}} 12$ de 02/01/2001 (ANVISA, 2001), que traz no seu Anexo I, os "Padrões Microbiológicos Sanitários para Alimentos".

Tabela 3 - Caracterização microbiológica das amostras de água da companhia de abastecimento local, efluente e efluente apósfiltragens com carvões

\begin{tabular}{|c|c|c|c|c|c|c|}
\hline Parâmetro* & Unidade & $\mathbf{A P} * *$ & EFL** & BIO** & COM** & $\begin{array}{l}\text { OMS } \\
(1989) \\
\end{array}$ \\
\hline $\begin{array}{l}\text { Coliformes } \\
\text { termotolerantes }\end{array}$ & $\begin{array}{c}\text { NMP/100 } \\
\mathrm{mL}\end{array}$ & $<1,810^{3}$ & $<2,710^{5}$ & $<2,510^{3}$ & $<2,110^{4}$ & $110^{3}$ \\
\hline
\end{tabular}

\subsection{Análise de solos}

Segundo Raij et al. (1996 apud EMBRAPA 2002), a magnitude dos valores individuais de cada nutriente presente no solo, bem como as variáveis deles (SB, CTC, V) conferem uma ideia do grau da fertilidade do solo, ou seja, de seu grau de capacidade de ceder nutrientes para as culturas; portanto, a Circular Técnica N $\mathrm{N}^{\circ} 63$ (EMBRAPA, 2002) aponta como devem ser realizadas as devidas interpretações de resultados de solos conforme parâmetros citados bem como realiza recomendações de eventuais correções do solo.

Conforme a Tabela 4, o solo inicialmente possuiu o valor de matéria orgânica (MO) de 19,9 g. $\mathrm{dm}^{-3}$ no qual no final do experimento observou-se um decréscimo no valor, principalmente no solo irrigado com efluente direto da ETE; entretanto, pode-se perceber que não houve uma diferenciação significativa entre os tratamentos. Segundo a EMBRAPA (2002), o solo inicial pode ser classificado com teor médio de MO e após tratamentos como teor baixo.

Segundo Duarte et al. (2008), o decréscimo dos valores da matéria orgânica se deve ao fato de que os microrganismos heterotróficos do solo utilizam os compostos orgânicos no qual possuem o nitrogênio como fonte energética e são responsáveis pela mineralização da matéria orgânica. Os autores ainda trazem que os efluentes são portadores de concentrações de carbono bem superiores do que as águas superficiais, o que torna positivo o desenvolvimento da biota do solo, no qual transforma o nitrogênio orgânico em nitrogênio assimilável às culturas. Portanto, a maior concentração de nitrogênio e carbono pode ter beneficiado a rápida mineralização e, por conseguinte, a diminuição dos teores de matéria orgânica dos solos desses tratamentos (DUARTE et al., 2008). 
Realizando o comparativo do valor de sódio no solo inicial e nos solos após as respectivas irrigações (final), observou-se o acréscimo nos tratamentos com efluente, situação afirmada por Cromer et al. (1984) e Barreto et al. (2013) que citam a elevação de sódio após a aplicação de águas residuárias com destaque principal em camadas superficiais. Pode-se observar também o acréscimo significativo no teor de sódio após irrigação com filtragem dos carvões, no qual o biocarvão apresentou-se praticamente na mesma escala comparando com o carvão comercial ativado.

A relação perpetua ao se analisar a Porcentagem de Sódio Trocável (PST), no qual os solos AP e o solo EFL apresentam um acréscimo esperado. Contudo, conforme Santos et al. (2018), os solos irrigados pelos efluentes filtrados pelos carvões (BIO e COM), por estarem enquadrados na faixa entre 6-15 \% nos parâmetros da EMBRAPA (2002), podem ser enquadrados como solos solódicos, precisando, deste modo, ter uma maior atenção à reutilização desses solos em culturas, atentando-se a um manejo adequado de irrigação e drenagem. Já para Walker e Bernal (2008), somente quando os níveis de PST do solo atingem $15 \%$ ele pode ser considerado sódico, acarretando em mudanças aos atributos estruturais e hidráulicos do mesmo.

Quanto ao parâmetro do pH do solo, os tratamentos não apresentaram diferenciação nos valores que, segundo EMBRAPA (2002), se encontram na zona da neutralidade (acidez e alcalinidade) e os resultados comportaram-se de acordo conforme o experimento com mamona de Barreto et al. (2013) no qual não constataram alterações no pH do solo irrigado com efluente.

Quanto ao fósforo e potássio, segundo os mesmos autores, os resultados obtidos foram um acréscimo de ambos no solo após aplicação de efluente tratado, conforme a Tabela 4, pode-se perceber que, para o potássio, houve um decréscimo dos valores para todos os tratamentos, exceto para o solo no qual o efluente filtrado pelo biocarvão apresentou-se praticamente com o mesmo valor, $70 \mathrm{cmolc} \mathrm{dm}^{-3}$, resultado benéfico pelo fato de manter este nutriente no solo, mesmo todos os resultados estarem classificados conforme a EMBRAPA

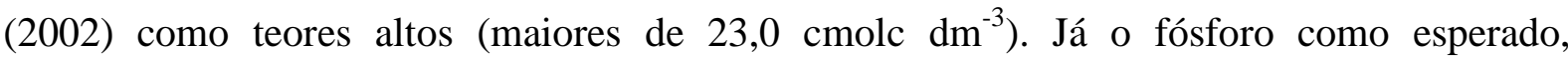
observou-se um acréscimo no solo irrigado com água da UFS pelo fato da adubação realizada, nos demais tratamentos o solo irrigado com o efluente filtrado pelo biocarvão apresentou melhor resultado, sendo $24,7 \mathrm{cmolc} \mathrm{dm}^{-3}$, resultado que mais se aproximou para atingir teor alto conforme EMBRAPA (2002), que seria solos com teores acima de 30,0 $\mathrm{cmolc} \mathrm{dm}^{-3}$. 
CARVALHO, R. S. et al. Tratamento de água residuária à base de biocarvão do bagaço de laranja para a irrigação

Tabela 4 - Caracterização físico-química do solo inicial e solo após irrigação por distintos tratamentos

\begin{tabular}{lcccccc}
\hline Parâmetro* & Unidade & Solo inicial & $\begin{array}{c}\text { Solo } \\
\text { AP** }\end{array}$ & Solo BIO** & $\begin{array}{c}\text { Solo } \\
\text { EFL** }\end{array}$ & $\begin{array}{c}\text { Solo } \\
\text { COM** }\end{array}$ \\
\hline M.O.*** & $\mathrm{g} \mathrm{dm}^{-3}$ & 19,9 & 11,3 & 11,3 & 11,1 & 12,2 \\
Sódio & $\mathrm{Cmolc} \mathrm{dm}^{-3}$ & 0,109 & 0,220 & 0,590 & 0,196 & 0,609 \\
PST & $\%$ & 2,22 & 3,82 & 9,73 & 3,52 & 9,85 \\
pH em SMP & - & 6,5 & 7,0 & 6,9 & 6,8 & 6,9 \\
Potássio & $\mathrm{Cmolc} \mathrm{dm}^{-3}$ & 74,0 & 47,0 & 70,0 & 25,6 & 36,2 \\
Fósforo & $\mathrm{Cmolc} \mathrm{dm}^{-3}$ & 22,6 & 44,1 & 24,7 & 21,7 & 22,8 \\
\hline
\end{tabular}

*PST: porcentagem de sódio trocável

**BIO: filtragem com biocarvão; AP: água da companhia de abastecimento local; COM: filtragem com carvão comercial ativado; EFL: efluente tratado. *** Matéria Orgânica

\subsection{Eficiência dos filtros}

Para mensurar a eficiência dos adsorventes, foi medido o volume filtrado até a observância de mudança de coloração nas filtragens, no qual nos primeiros filtros construídos foram de 3,6 litros de volume filtrado para o carvão comercial ativado e 4,6 litros de volume filtrado para o biocarvão. Quando foi realizada a repetição das filtragens, foi observado que, para o carvão comercial ativado, foram de 2,8 litros e 4,2 litros para o biocarvão. Portanto pode-se concluir que a média de eficiência do filtro utilizado com biocarvão do bagaço da laranja foi em média $25 \%$ maior do que o filtro utilizado com carvão comercial ativado. A massa dos carvões usados nos filtros foi de 480 gramas.

\section{CONCLUSÃO}

A utilização de bioadsorventes no tratamento terciário de águas residuárias é positiva em diversas pesquisas objetivando a melhoria da qualidade das mesmas. Neste contexto, o biocarvão à base do bagaço de laranja apresentou resultados promissores no que diz respeito a ser um tratamento terciário em efluente doméstico pós-tratamento secundário (lagoas de estabilização) para irrigação na agricultura.

A irrigação com efluente tratado após filtragem com o biocarvão e o carvão comercial ativado não influenciaram representativamente nas variáveis agronômicas: massa do bulbo, diâmetro transversal e diâmetro longitudinal da cultura do rabanete, ou seja, não ocorreram diferença significativa de $5 \%$ de probabilidade pelo teste de Tukey possibilitando, portanto, ser possível utilizá-las. Quanto à microbiologia, os resultados com o efluente filtrado com o 
biocarvão, apesar de não ter atendido à OMS, apresentou os melhores valores entre os efluentes.

Nas análises físico-químicas da água da UFS e dos efluentes, pode-se observar que todos os parâmetros foram atendidos pela Resolução CONAMA Nº 357/2005 e/ou trabalhos voltados a irrigação com reuso. Já os valores da condutividade elétrica das águas alertam ao risco de salinização do solo, fator corroborado quando se analisaram os teores de sódio no solo; portanto, deve-se atentar ao reuso na agricultura, no sentido de ser utilizado para a aplicação em solos bem drenados e que as espécies cultivadas deverão apresentar alta tolerância salina.

Os resultados obtidos ao longo do presente trabalho permitiram concluir a possibilidade de conversão de um resíduo da agroindústria de baixo valor e sem destinação apropriada pelas indústrias de suco, transformando em um produto de valor agregado, um biocarvão, portador de um potencial de ser usado como tratamento terciário para o reuso de água voltado à irrigação de culturas.

\section{REFERÊNCIAS}

ABREU, I. Ambiente e pobreza. Artigo de divulgação. Disponível em: http://www.naturlink.pt. 2007. Acesso em: 13 out. 2020.

ALLEN, R. G. et al. Método FAO-56 de coeficiente de cultura dupla para estimar a evaporação do solo e extensões de aplicação. Jornal de engenharia de irrigação e drenagem, Reston, v. 131, n. 1, pág. 2-13, 2005.

ANA. AGÊNCIA NACIONAL DE ÁGUAS. 2011. Campanha "água é vida e vidanão se desperdiça". Disponível em: http://www.ana.gov.br/SalaImprensa/aguavida/aguavida.asp. Acesso em: 22 ago. 2020.

AGÊNCIA NACIONAL DE VIGILÂNCIA SANITÁRIA - ANVISA. Resolução RDC n 12 de 02 de janeiro de 2001 - Estabelece os padrões microbiológicos sanitários para alimentos especificados no Anexo I e determiner os critérios para a conclusão e interpretação dos resultados das analyses microbiológicas de alimentos destinados ao consumo humano especificados no Anexo II.

BARRETO, A. N. et al. Changes in chemical attributes of a fluvent cultivated with castor bean and irrigated with wastewater. Revista Brasileira Engenharia Agrícola Ambiental, Campina Grande, v. 17, n. 5, p. 480-486, 2013.

BRASIL. Resolução Conselho Nacional de Recursos Hídricos $\mathbf{n}^{\circ}$ 54, de 28 de novembro de 2005. Estabelece critérios gerais para reúso de água potável. Estabelece modalidades, diretrizes e critérios gerais para a prática de reúso direito não potável de água, e dá outras providências. Brasília: DOU, 2005. 
BRASIL. Ministério da Agricultura, Pecuária e Abastecimento. Projeções do Agronegócio. Brasil 2019/20 a 2029/30. Projeções de Longo Prazo. 2020. Disponível em: https://www.gov.br/agricultura/pt-br/assuntos/noticias/ao-completar-160-anos-ministerio-daagricultura-preve-crescimento-de-27-na-producao-de-graos-do-pais-na-proximadecada/ProjecoesdoAgronegocio2019_20202029_2030.pdf. Acesso em: 22 jun. 2021.

CAHILL, M. The implications of consumerism for the transition to a sustainable society. Social Policy \& Administration, Nova Jersey, v. 35, n. 5, p. 627-639, 2003.

CARVALHO, R. S. et al. Influência do reuso de águas residuárias na qualidade microbiológica do girassol destinado à alimentação animal. Ambi-Água, Taubaté, v. 8, n. 2, p. 157-167, 2013.

CETESB. Companhia Ambiental do Estado de São Paulo. Orientação para apresentação de projeto visando a aplicação de água de reuso proveniente de estação de tratamento de esgoto doméstico na agricultura. Aplicação de água de reuso de ETE na agricultura. São Paulo, 2006. 11 p. Disponível em: http://www.cetesb.sp.gov.br/areas-contaminadas/manualde-gerenciamento-de-areas-contaminadas/7-manual-de-gerenciamento-das--acs. Acesso em: 20 set. 2020.

CONAMA. Conselho Nacional de Meio Ambiente. Resolução n ${ }^{\circ} 357$, de 17 de março de 2005 publicada no dou n ${ }^{\circ} 053$, de 18/03/2005, págs. 58-63. Dispõe sobre a classificação dos corpos de água e diretrizes ambientais para o seu enquadramento, bem como estabelece as condições e padrões de lançamento de efluentes, e dá outras providências. Brasília: DOU, 2005.

COSTA JUNIOR, S. S. et al. Produção de carvão ativado quimicamente com $\mathrm{Al}_{2}\left(\mathrm{SO}_{4}\right)_{3} \mathrm{e}$ remoção de contaminante orgânico. In: CONGRESSO BRASILEIRO DE QUÍMICA, 54. , 2014, Natal. Anais[...]. Natal, 2014.

CROMER, R. N. et al. Irrigation of monterey pine with wastewater: effect on soil chemistry and ground water composition. Journal of Environmental Quality, Madison, v. 13, n. 4, p. 539-542, 1984.

CUBA, R. S. et al. Potential of domestic sewage effluent treated as a source of water and nutrients in hydroponic lettuce. Ambiente e Água - Na Interdisciplinary Journal of Applied Science, Taubaté, v. 10, n. 3, p. 574-586, 2015.

CUNHA, V. D. Estudo para proposta de critérios de qualidade da água para reuso urbano. 2008. 106 f. Dissertação (Mestrado em Engenharia) - Universidade São Paulo, São Paulo, 2008.

DANTAS, I. L. de A. et al. Viabilidade do uso de água residuária tratada na irrigação da cultura do rabanete (Raphanus sativus L.). Revista Ambiente e Água, Taubaté, v. 9, n. 1, p. 109-117, 2014. 
DUARTE, A. S. et al. Efeitos da aplicação de efluente tratado no solo: pH, matéria orgânica, fósforo e potássio. Revista Brasileira Engenharia Agrícola Ambiental, Campina Grande, v. 12, n. 3, p. 302-310, 2008.

EMBRAPA. Empresa Brasileira de Pesquisa Agropecuária. Adubação e correção do solo: procedimentos a serem adotados em função dos resultados da análise do solo. Rio de Janeiro, 2002.

FACCIOLI, G. G. et al. Análise das características agronômicas e microbiológicas do feijãocaupi (Vigna ungiculada (L.) Walp.) brs novaera e brs guariba com aplicação de água residuária tratada. Revista Brasileira de Agricultura Irrigada, Fortaleza, v. 11, n. 5, p. 1707-1713, 2017.

FILGUEIRA, F. A. R. Novo manual de olericultura: agrotecnologia moderna na produção e comercialização de hortaliças. Viçosa: UFV, 2012. 421 p.

FIORENTIN, L. D. et al. Isotermas de sorção do resíduo agroindustrial bagaço da laranja. Revista Brasileira de Engenharia Agrícola e Ambiental, Campina Grande, v. 14, n. 6, p. 635-659, 2010.

KORAA, A. et al. Reuse of urban wastewater by combined stabilization pond system em Benslimane (Marocco).Urban Water, Amsterdam, n. 4, p. 373-378, 2002.

OLIVEIRA, P. C. et al. Produção de moranga irrigada com esgoto doméstico tratado. Revista Brasileira Engenharia Agrícola Ambiental, Campina Grande, v. 17, n. 8, p. 861-867, 2013.

RAIJ, B. V. et al. Recomendações de adubação e calagem para o Estado de São Paulo, 2. ed. Campinas: Instituto Agronômico \& Fundação IAC, 1996. 285p. (Boletim técnico, 100).

REBOUÇAS, A. C.; BRAGA, B.; TUNDISI, J. G. Águas doces no Brasil: capital ecológico, uso e conservação. 3. ed. São Paulo: Escrituras, 2006. 748 p.

ROLIM, H. O. et al. Qualidade dos efluentes de sistemas de tratamento biológico UASB e UTC para reúso agrícola. Revista em Agronegócio e Meio Ambiente, Maringá, v. 9, n. 2, p. 393-414, 2016.

SANTOS, H. G. et al. Sistema brasileiro de classificação de solos. Brasília: Embrapa, 2018.

TEIXEIRA, M. T.; SANTOS, L. F.; SANTANA, H. F. Meios filtrantes para água de uso doméstico. Revista Científica Univiçosa, Viçosa, v. 7, n. 2, p. 265-270, 2015.

WALKER, D. J.; BERNAL, M. P. The effects of olive mill waste compost and poultry manure on the availability and plant uptake of nutrients in a highly saline soil. Bioresource Technology, Lucknow, v. 99, n. 2, p. 396 - 403, 2008.

WHO. World Health Organization. Health guidelines for the use of wastewater in agriculture and aquaculture. Technical report series 778. Geneva: World Health Organization. 1989. 


\section{DADOS DOS AUTORES:}

Nome: Roseanne Santos de Carvalho

E-mail: roseanne.carvalho@ifs.edu.br

Curriculum Lattes: http://lattes.cnpq.br/5272493744813898

Doutorado e mestrado em Desenvolvimento e Meio Ambiente pela Universidade Federal de Sergipe e graduação em Engenharia Civil pela Universidade Federal de Sergipe. Professora do Instituto Federal de Sergipe na área de Edificações. Integrante do Grupo de Pesquisa ACQUA vinculado ao Prodema/CNPq e líder de Grupo de Pesquisa Água e energia vinculado ao IFS/CNPQ; tem experiência na área de Engenharia Civil, atuando principalmente com as temáticas: Meio Ambiente, Interdisciplinaridade, Escassez de água e seu reuso, Políticas Públicas e Sustentabilidade.

Nome: Beatriz Feitosa Sandes dos Santos

E-mail: b.fsandes@gmail.com

Curriculum Lattes: http://lattes.cnpq.br/0467919908309270

Mestranda em Desenvolvimento e Meio Ambiente na Universidade Federal de Sergipe e graduação em Engenharia Civil pelo Instituto Federal de Sergipe. Pesquisadora sobre a temática reuso de águas residuárias.

Nome: Gregorio Guirado Faccioli

E-mail: gregorioufs@gmail.com

Curriculum Lattes: http://lattes.cnpq.br/4563644185421346

Pós-doutorado na Universidade de Sevilha - Espanha no Departamento de Geografia Física, doutorado, mestrado e graduação em Engenharia Agrícola pela Universidade Federal de Viçosa na área de concentração de Irrigação e Drenagem. Tem experiência na área de Engenharia Agrícola, com ênfase em Irrigação e Drenagem, atuando principalmente nos seguintes temas: evapotranspiração de referência, evapotranspiração da cultura, irrigação, manejo da irrigação, reuso de águas residuárias e índice de sustentabilidade. Professor Associado do Departamento de Graduação em Engenharia Agrícola da Universidade Federal de Sergipe. Bolsista Produtividade nível 2.

Nome: Maria de Lara Palmeira de Macedo Arguelho

E-mail: laurapalm@yahoo.com

Curriculum Lattes: http://lattes.cnpq.br/1396973634283242

Doutorado e mestrado em Ciências pela Universidade de São Paulo e graduação em Química pela Universidade Federal de Mato Grosso do Sul e História pela Universidade Estácio de Sá, Atualmente é Professora Associada na Universidade Federal de Sergipe onde leciona disciplinas de Química Geral, Analítica e Ambiental, na pesquisa vem atuando principalmente na área de Analítica Ambiental e nos seguintes temas: a) desenvolvimento e aplicação de metodologias para análise e tratamento de efluentes; b) monitoramento químico de água e sedimento em ambiente marinho e zonas costeiras e c) desenvolvimento de embalagens ecológicas a partir de resíduos da indústria alimentícia.

Nome: Erik Santos Passos

E-mail: erikspassos@ gmail.com

Curriculum Lattes: http://lattes.cnpq.br/3868466830120511

Mestrando em Desenvolvimento e Meio Ambiente na Universidade Federal de Sergipe e graduação em Engenharia Civil pelo Instituto Federal de Sergipe. Tem experiência em filtros 
para tratamento de efluentes, produção de biocarvão, tratamentos de águas cinzas, reuso de efluentes domésticos na agricultura. Atua nas seguintes áreas: Recursos Hídricos e Saneamento.

Nome: Romulo Alves de Oliveira

E-mail: romulo.oliveir@uol.com.br

Curriculum Lattes: http://lattes.cnpq.br/5042455649809629

Doutorado e mestrado em Engenharia Elétrica pela Universidade Federal do Rio Grande do Norte e graduação em Engenharia Elétrica pela Universidade Federal da Paraíba. Atualmente é professor do Instituto Federal de Sergipe. Tem experiência na área de Engenharia Elétrica, com ênfase em Eficiência Energética e Fontes Alternativas de Energia. 